DOI: $10.17951 / \mathrm{ff} .2018 .36 .2 .173-181$

\begin{tabular}{|c|c|c|}
\hline U N I & $\begin{array}{l}\text { ANNALE } \\
\text { MARIAECI } \\
\text { BLIN - POI }\end{array}$ & \\
\hline VOL. XXXVI & SECTIO FF & $2-2018$ \\
\hline
\end{tabular}

\author{
ОЛЬГА ЯКОВЛЕВА/OLGA IAKOVLEVA \\ Uniwersytet Marii Curie-Skłodowskiej \\ ORCID ID: https://orcid.org/0000-0001-5124-6412
}

\title{
Фразеологический потенциал рекламных слоганов
}

Phraseological Potential of Advertising Slogans

Potencjał frazeologiczny sloganów reklamowych

В связи с медиатизацией жизненного пространства современного общества, становлением и развитием медиалингвистики, различные сферы массовой речевой коммуникации становятся объектом изучения многих междисциплинарных исследований. В настоящее время особое внимание исследователями уделяется изучению языка рекламы. В частности, рассматриваются лингвостилистические особенности рекламных текстов (Д.Э. Розенталь, Н.Н. Кохтев, Е.С. Кара-Мурза, Т.Г. Добросклонская, Х. Кафтанджиев, Е.Ю. Жданова, М.В. Старовойт), языковая игра в рекламном дискурсе (Л.П. Амири, С.В. Ильясова, Ю.К. Пирогова, Н.В. Лазовская), различные аспекты функционирования фразеологических единиц в рекламе (Е.В. Куликова, Е.М. Гирняк, А.И. Казанцев, И.И. Новосельцева, И.В. Высоцкая), проблема перевода рекламных слоганов (Е.В. Медведева, О.А. Бондарева, Н.С. Жукова, И.В. Борнякова), национально-культурная специфика рекламных текстов (Н.О. Долгих, В.В. Бегун, Я.Н. Романенко, М.В. Маслова, А.Н. Магомедова, А.М. Хайбулаева) и т.д.

Двусторонность связи между фразеологией и рекламой обусловлена активным использованием фразеологических единиц (в узуальном или трансформированном виде) в рекламных текстах, с одной стороны, и фразеологизацией рекламных слоганов - с другой. Под рекламным слоганом нами понимается лаконичная, оригинальная фраза, содержащая суть рекламной идеи. В статье рассматриваются рекламные слоганы, неоднократно использованные в публикациях российских периодических изданий за период с 2000 
по 2010 гг. В качестве иллюстративного материала была использована авторская картотека фразеологизмов, составленная методом сплошной выборки из публикаций современной российской прессы (включая Интернет-издания).

Как отмечает E.M. Гирняк (Girniak, 2011:33), «в основе создания рекламных текстов лежат две тенденции: сжатость, лаконичность выражения и выразительность, емкость информации». Рекламные слоганы по своей природе афористичны, близки к фразеологической единице, поскольку обладают схожими качествами - ярким, образным содержанием и краткой формой.

Специалисты по рекламе создают массу рекламных слоганов, которые впоследствии транслируются в телевизионных роликах, на радио и в печатных периодических изданиях. В настоящее время наблюдается активная фразеологизация сочетаний слов, используемых в рекламных текстах. Главным условием перехода рекламного слогана в устойчивое выражение, по мнению самих создателей рекламных текстов, является его универсальность, «многосмысленность» и злободневность (Moskalenko, 1998). Узнаваемости, запоминанию рекламного слогана способствует его многократное (даже назойливое) и регулярное воспроизведение в СМИ.

Немаловажным обстоятельством является и тот факт, что реклама ориентирована прежде всего на широкую потребительскую аудиторию. Поэтому в рекламный слоган включаются разговорные конструкции, сленговые слова и обороты, привычные формы речевого общения. Ситуации, представленные в рекламных роликах, потенциальные покупатели товаров и услуг переносят в ситуации в своей жизни, уже «сформировался целый рекламный цитатник на каждый день, с помощью которого без особых затруднений можно выразить всю гамму человеческих эмоций» (Moskalenko, 1998).

Среди различных жанров рекламы в деле популяризации рекламных слоганов главная роль, без сомнения, принадлежит телевизионному рекламному ролику. Нельзя не согласиться с Ю.Б. Пикулевой (Pikuleva, 2006:9), которая отмечала, что «телевизионная реклама претендует на выработку культурноэтических, коммуникативных и речевых стандартов. Именно телевизионная реклама (в отличие от радио- и печатной) обладает особой воздействующей силой, порождает прецедентные знаки и формирует «языковой вкус эпохи».

Время существования рекламных слоганов специфично, поскольку ограничено продолжительностью рекламной кампании. Пока в эфире постоянно транслируется рекламный ролик, фразы из него, будучи у всех на слуху, непроизвольно запоминаются, входят в сознание. Но с прекращением выхода рекламы в эфир многие выражения уходят из памяти, и только часть рекламных фраз продолжает функционировать вне рекламного пространства. 
Так, например, произошло с рекламным слоганом из рекламы шампуня «Vidal Sassoon»: Vidal Sassoon. Шампунь и кондиционер в одном флаконе. Рекламный ролик транслировался в эфире в начале 90-х гг., и по прошествии достаточно длительного периода обороты из этой рекламы продолжают функционировать в разговорной речи, в дискурсе масс-медиа. Из рекламного текста в общеупотребительный лексикон вошли словосочетания два в одном и в одном флаконе.

После появления рекламы, представляющей совмещенный продукт, словосочетание два в одном стало активно использоваться в ситуациях, когда речь шла о каких-либо косметических средствах, решающих одновременно несколько задач (лосьон-тоник, крем-мыло), товарах-гибридах (юбка-брюки, фен-щетка):

Куртки-трансформеры «Два в одном»: к базовой верхней куртке пристегивается пуховая подстежка [«Комсомольская правда», 20.10.2005].

Разумеется, предметы, совмещающие в себе две и более функций, были известны задолго до появления рекламы шампуня (например, плащ-палатка). Тем не менее, именно реклама послужила источником для появления простого и емкого выражения два в одном, обозначающего целый класс подобных предметов. По мере своего распространения оборот два в одном иногда стал употребляться в ситуации, когда покупателям предлагалось приобрести два товара (или услуги) по цене одного:

К такой системе «агрессивных» скидок тяготеют магазины, продающие одежду, обувь, сумки. Второй путь - «два в одном». То есть, две вещи по одной цене [«Комсомольская правда», 09.12.2002].

На страницах газет устойчивые выражения два в одном и в одном флаконе употребляются в значении 'вместе, одновременно с чем-л. другим':

Но я хотел бы еще раз напомнить, что единый экзамен - это, как шутят журналисты, «два в одном», совмещение выпускного экзамена со вступительным» [«Труд-7», 17.07.2001].

Что называется «два в одном»: взять деньги за «обследование» да плюс к тому продать более чем сомнительные препараты [«Труд-7», 05.05.2004].

Появились многофункциональные устройства (МФУ) - это принтер, сканер, копир и персональная фотолаборатория в одном флаконе [«Комсомольская правда», 16.11.2005].

Вероятно, что фразеологизации данного слогана способствовала потребность в вербализации осознаваемого, но еще не получившего наименования 
понятия. Вслед за популярной формулой два в одном по аналогии появились схемы «три в одном», «четыре в одном» и т.д.:

Три в одном. Сегодня девелоперы создают универсальные поселки, сочетающие в себе недвижимость различных типов - коттеджи, таунхаусы и малоэтажные дома [«Известия», $12.09 .2006]$

Лучше всего взять «четыре в одном» - пишущий DVD-привод (CD-ROM/CD-RW/DVDROM/D VD-RW) [«Комсомольская правда», 06.10.2004].

Интересным примером фразеологизации рекламных слоганов служит фраза из рекламы шоколадного батончика «Шок»: «Шок - это по-намему!». Как и в предыдущем случае, реклама активно транслировалась на телевидении в 90-х гг., а в настоящее время фразеологизм из рекламного текста используется в обиходно-разговорной речи, в публикациях газет и журналов. Заимствованное из французского языка слово шок в толковом словаре имеет следующие значения: 1. Своеобразная реакция организма на воздействие сильных внешних раздражителей (при травме, ожоге, введении чужеродного белка, психической травме и т.п.), выражающаяся резким нарушением нервной регуляции жизненных процессов. 2. Состояние крайней растерянности или подавленности (Kuznetsov 2002:1502). Рекламный фразеологизм шок это по-нашему употребляется в газетных публикациях в значении 'сильное удивление от чего-либо или от кого-либо':

Шок - это по-нашему... [...] В Норильском заполярном театре драмы еще вчера полным ходом шла подготовка к фестивалю [...]. Новость, что фестиваль не состоится, стала для театра, мягко говоря, шокирующим сюрпризом [«newslab.ru», 11.09.2009].

«Шокирующих» событий, фактов в прессе множество - от экзаменов до лишения родительских прав женщины, родившей мертвого ребенка:

Шок-это по-нашему. Чтобы оценить последствия введения дополнительных обязательных экзаменов для выпускников школ, надо на несколько минут оказаться на месте родителей и ребят [«Mediazavod.ru», 26.01.2009].

Шок - это по-нашему. История о том, как через пять с половиной лет мертвый ребенок вдруг ожил [«Вятский край», 11.04.2003].

На наш взгляд, рекламный слоган шок - это по-намему очень удачно попал в культурно-исторический контекст развития российского общества. Социально-политическая нестабильность, глубокий экономический кризис и реформирование экономической системы путем шоковой терапии - в таких 
условиях проходило формирование общества в новой России. Нахождение в постоянном напряжении, стрессе стало в какой-то степени привычным для многих людей. Поэтому фразу «по-нашему» можно воспринимать как «по-российски», как то, что свойственно для российского общества. Немаловажным является и тот факт, что время появления анализируемого рекламного текста относится к одному из самых сложных периодов (90-е гг. ХХ в.) постперестроечной России.

Помимо прямого цитирования, рекламный фразеологизм шок - это понашему используется в материалах газет в трансформированном виде, например, как вопросительно-утвердительная конструкция:

Шок? Это по-нашему! Семидесятилетняя жительница Железногорского района Анна Петровна Гарахова недавно испытала шок. Из скромной пенсии бывшей колхозницы удержали 700 рублей за долги по оплате квартиры в городе Железногорске, где она никогда не была и никогда не жила [«Курская правда», 04.04.2006].

Необходимо подчеркнуть, что рекламный фразеологизм шок - это понашему употребляется и в ситуациях, не связанных с какими-либо негативными событиями или явлениями. Иногда с помощью этой фразы выражается чувство удивления от чего-то необычного, непривычного, носящего провокационный характер:

Шок- это по-нашему! В этом театре играют не только артисты, но и... зрители. Артисты театра любят эксперименты. Их искусство шокирует [«KM.RU», 04.04.2002].

Появление нейтральной окраски у фразеологизма шок - это по-нашему может быть связано с процессами, происходящими со словосочетанием быть в шоке ('удивляться, возмущаться; быть сильно испуганным'), у которого в настоящее время активно развивается дополнительное значение с положительной коннотацией - 'быть приятно удивленным':

Меня так любили болельщики, я был потрясен их отношением ко мне... - Даже часы легендарного тренера Николая Карпова, который дважды приводил «Спартак» к золотым медалям, вам подарили. - Я был в шоке! И если бы только часы [«Советский спорт», 16.10.2010].

Утратив непосредственную связь с рекламируемым товаром, брендом, слова и обороты из рекламных текстов в ряде случаев начинают употребляться в повседневной речи как экспрессивные синонимы уже известных слов и выражений. Так, например, произошло со словом не айс из рекламы жевательной резинки «Stimorol». В переводе с английского языка слово «айс» означает «лёд» (англ. «ісе»). В контексте рекламы слово «айс» приобрело оценочную 
коннотацию - «что-то хорошее, положительное». Попутно отметим, что в настоящее время в повседневной речевой практике (особенно среди молодежи) в подобном значении активно употребляется слово «огонь». Впоследствии слово «не айс» стало употребляться в различных коммуникативных ситуациях со значением «не очень хорошо, посредственно» (ср. «уже не торт», «не фонтан»). Приведем фрагмент публикации из периодической печати:

Как говорится, и все-то мы знаем, и везде-то мы бывали. Уже и Турция нам «не айс», и в Египте нам нравится не все, а только отдельные места, и в Пхукет мы еще, куда ни шло, но в Паттайю - ни ногой [«Труд-7», 23.05.2007].

C рекламой жевательной резинки «Stimorol» связан также рекламный слоган Иногда лучше жевать, чем говорить. Данный слоган является синонимичным по своему значению известному фразеологизму язык мой - враг мой. Именно в таком значении рекламный слоган используется в текстах газет:

Иногда лучше жевать, чем говорить. Известный телерепортер Питер Арнетт был уволен американской телекомпанией Эн-би-си за то, что в интервью своим иракским коллегам признал, что план войны против Саддама Хусейна провалился и что иракские власти хорошо обращаются с иностранными журналистами [«Труд», 02.04.2003].

Одним из главных условий удачного, запоминающегося рекламного слогана (кроме краткости, оригинальности, экспрессивно-эмоциональной окрашенности) является наличие подтекста, яркой образной составляющей. Поэтому при создании рекламных текстов авторы нередко прибегают к метафоре. Лаконичный, эффектный рекламный слоган И пусть весь мир подождет! хорошо запомнился по рекламе творожка «Даниссимо». Товар в указанной рекламе представляется в гиперболизированном виде: продукт настолько хороший, что момент удовольствия, получаемого от этого продукта, становится исключительным. Рекламный слоган содержит положительный посыл, адресованный клиенту. За пределами коммерческого контекста слоган приобретает ироническую окраску, используется в ситуации, когда кто-либо не считается с интересами других людей, проявляет неуважение к их времени. Так, под заголовком «Зацепило! И пусть весь мир подождет» автор публикации комментирует задержку авиарейса по просьбе одного известного актера:

Умиляться тому, что полторы сотни людей потели в своих креслах, чтобы одна звезда успела расцеловать в щечки другую, я не готов [«Комсомольская правда», 20.11.2007].

Запоминанию рекламных слоганов способствуют также рифмованные строки: Попробовав раз, ем и сейчас (реклама чипсов «Pringles»); Свежее 
дыхание облегчает понимание (реклама конфет «Рондо»). Результатом фразеологизации рекламных слоганов являются такие выражения, как: сладкая парочка; не тормози - сникерсни; не все йогурты одинаково полезны; райское наслаждение; заплати и спи спокойно; новое поколение выбирает «Пепси»; ты этого достойна; хорошо иметь домик в деревне и другие.

В некоторых случаях популярные рекламные слоганы, попадая на страницы газет, подвергаются структурной трансформации. Иллюстрацией может послужить рекламный слоган из рекламы безалкогольного напитка «Спрайт»: Имидж - ничто. Жажда - всё! Sprite. Не дай себе засохнуть. Как правило, в структуре слогана не дай себе засохнуть происходит замена последнего компонета:

не дай себе промокнуть [«Труд», 12.08.2002], не дай себе сопреть [«Утро.ru», 19.04.2001], не дай себе замерзнуть [«Московский комсомолец», 10.10.2002], не дай себе задуматься [«Нева», 2008, 7] и т.д.

Как справедливо отмечает В. Хлебда (Chlebda, 1996), процесс трансформации какой-либо группы словосочетаний является подтверждением ее постоянства. На наш взгляд, различные преобразования рекламного слогана свидетельствуют о его жизнеспособности, продуктивности модели.

Интересным явлением, связанным с фразеологизацией рекламных текстов, является цитирование в рекламном тексте популярного, узнаваемого слогана из другой рекламы. Зачастую реклама для какого-либо товара, торговой марки создается с учетом накопленного опыта, в рекламные тексты включаются удачные, проверенные временем рекламные слоганы из других реклам. К примеру, в рекламе стирального порошка «Тide» использовались слоганы, среди которых («Найти и обезвредить!», «Операция «Кипячение», «Чистота - чисто Тайд») особую популярность приобрел рекламный слоган Bbl все еще кипятите? Тогда мы идем к Вам!, послуживший своего рода шаблоном, по которому писались тексты для новых реклам:

Clojure, или «Bы все еще используете Java? Тогда мы идем к вам!» (реклама функционального языка Clojure), Вы всё ещё машете тапком? Тогда мы идём к Вам! (реклама услуг компании «ЭВС» - Экологической Ветеринарной Службы).

Другой иллюстрацией может послужить успешная рекламная кампания «Sprite», запомнившаяся ярким слоганом Имидж-ничто. Жажда-всё! Sprite. Не дай себе засохнуть. Его непрямое цитирование находим в различных рекламах:

Имидж - ничто, Honda - Bce! (реклама автомобиля марки «Ноnda»), Термобелье - не дай себе замерзнуть! и т.д. 
Фразеологизированные рекламные слоганы по числу цитирований сопоставимы с другими источниками новых фразеологизмов современного русского языка, что свидетельствует о серьезном фразеологическом потенциале рекламных слоганов. Рекламные слоганы, войдя в речевой обиход носителей языка, начинают активно использоваться ими в различных коммуникативных ситуациях, как и другие устойчивые выражения (паремии, афоризмы, крылатые фразы). Резюмируя результаты нашего исследования, можно предположить, что постоянное развитие рекламной сферы, информационных и телекоммуникационных технологий в дальнейшем усилит процесс фразеологизации ряда рекламных слоганов, а также влияние рекламы на общество и речевую деятельность носителей языка.

\section{BIBLIOGRAFIA}

Chlebda, W. (1996). Frazeologia w reklamie i reklama we frazeologii. Problemy Frazeologii Europejskiej, 1, s. 57-68.

Girniak, E.M. (2011). Idiomatichnost reklamnogo teksta (na materiale russkoy i kitayskoy reklamy). Vestnik Permskogo Universiteta. Rossiyskaya i Zarubezhnaya Filologia, 1(13), s. 32-38. [Гирняк, Е.М. (2011). Идиоматичность рекламного текста (на материале русской и китайской рекламы). Вестник Пермского университета. Российская и зарубежная филология, 1(13), c. 32-38.]

Kuznetsov, S.A. (2002). Bolshoi tolkovyi slovar russkogo yazyka. Sankt-Peterburg: Norint. [Кузнецов, С.А. (2002). Большой толковый словарь русского языка. Санкт-Петербург: Норинт.]

Moskalenko, G. (1998). Teksty telereklamy rossiyane prevrashchayut w aforizmy. Kapital. Pobrano z: http://www.iccg.ru/ru/reception/press/?id=142\&f=97 (dostup: 11.02.2018). [Москаленко, Г. (1998). Тексты телерекламы россияне превращают в афоризмы. В: Капитал. Режим доступа: http://www.iccg.ru/ru/reception/press/?id=142\&f=97 (доступ: 11.02.2018).]

Pikuleva, Y.B. (2006). Televizionnaya reklama i yazykovoy vkus epohi. Filologicheskiy Klass, 16. Pobrano z: https://cyberleninka.ru/article/n/televizionnaya-reklama-i-yazykovoy-vkus-epohi (dostup: 11.02.2018). [Пикулева, Ю.Б. (2006). Телевизионная реклама и языковой вкус эпохи. Филологический класс, 16. Режим доступа: https://cyberleninka.ru/article/n/televizionnaya-reklama-i-yazykovoy-vkus-epohi (доступ: 11.02.2018).]

\section{ABSTRAKT}

Artykuł poświęcono sloganom reklamowym jako jednemu ze źródeł nowych jednostek frazeologicznych. Celami badania są przegląd uwarunkowań przejścia sloganów do grupy frazeologizmów reklamowych i analiza specyfiki funkcjonowania sloganów reklamowych we współczesnej prasie rosyjskiej. Materiał źródłowy stanowi autorska kartoteka frazeologizmów zebrana metodą przypadkowego wyboru z publikacji współczesnej rosyjskiej prasy (w tym również elektronicznych wersji periodyków) z lat 2000-2010. Wykorzystano następujące metody: opisową, analizy definicji słownikowych i analizy kontekstualnej. Sfrazeologizowane slogany reklamowe są produktywnym źródłem nowych frazeologizmów współczesnego języka rosyjskiego. Wchodzą do potocznego obiegu 
użytkowników języka i zaczynają być aktywnie wykorzystywane w różnych sytuacjach komunikacyjnych, podobnie jak inne stałe połączenia wyrazowe (paremie, aforyzmy, skrzydlate słowa).

Słowa klucze: slogan reklamowy, slogan, jednostki frazeologiczne

\begin{abstract}
The article is dedicated to advertising slogans as one of the sources of new phraseological units. The aim of the study is to review the determinants of the transfer of slogans to the group of advertising phraseologies and the analysis of the specificity of advertising slogans in the contemporary Russian press. As the source of the material, an original list of phraseologisms collected by the method of random selection from the contemporary Russian press publications (including electronic versions of periodicals) for the years 2000-2010, was used. The following methods were applied: a descriptive method, a method of dictionary definition analysis, a method of contextual analysis. Phraseologized advertising slogans are a source of new phraseologisms of the contemporary Russian language. Advertising slogans, similarly to paroemia, aphorisms, or winged words, begin to be actively used by the language users in various communication situations.
\end{abstract}

Keywords: advertising slogan, slogan, phraseological units

\begin{abstract}
АННОТАЦИЯ
Статья посвящена рекламным слоганам как одному из источников новых фразеологических единиц. Целью исследования является рассмотрение условий перехода слогана в разряд рекламных фразеологизмов, анализ особенностей функционирования рекламных слоганов в современной российской прессе. В качестве иллюстративного материала была использована авторская картотека фразеологизмов, составленная методом сплошной выборки из публикаций современной российской прессы (включая Интернет-издания) за период с 2000 по 2010 гг. Использованные методы: описательный метод, метод анализа словарных дефиниций, метод контекстуального анализа. Фразеологизированные рекламные слоганы являются продуктивным источником новых фразеологизмов современного русского языка. Рекламные слоганы, войдя в речевой обиход носителей языка, начинают активно использоваться ими в различных коммуникативных ситуациях, как и другие устойчивые выражения (паремии, афоризмы, крылатые фразы).
\end{abstract}

Ключевые слова: рекламный слоган, слоган, фразеологические единицы 